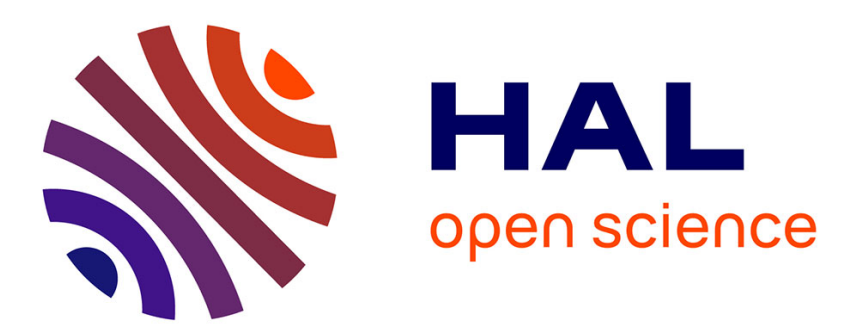

\title{
A review and perspective on context-dependent genetic effects of extra-pair mating in birds \\ Tim Schmoll
}

\section{To cite this version:}

Tim Schmoll. A review and perspective on context-dependent genetic effects of extra-pair mating in birds. Journal für Ornithologie = Journal of Ornithology, 2011, 152 (S1), pp.265-277. 10.1007/s10336011-0683-4 . hal-00685386

\section{HAL Id: hal-00685386 \\ https://hal.science/hal-00685386}

Submitted on 5 Apr 2012

HAL is a multi-disciplinary open access archive for the deposit and dissemination of scientific research documents, whether they are published or not. The documents may come from teaching and research institutions in France or abroad, or from public or private research centers.
L'archive ouverte pluridisciplinaire HAL, est destinée au dépôt et à la diffusion de documents scientifiques de niveau recherche, publiés ou non, émanant des établissements d'enseignement et de recherche français ou étrangers, des laboratoires publics ou privés. 
1 A review and perspective on context-dependent genetic effects of extra-pair mating in 2 birds

3

4 Tim Schmoll

5

6 Evolutionary Biology, University of Bielefeld, Morgenbreede 45, 33615 Bielefeld, Germany 7

8 Current address: Institute of Evolutionary Biology, The University of Edinburgh, King's

9 Buildings, Ashworth Laboratories, Edinburgh, EH9 3JT, United Kingdom

10

11 Corresponding author: Tim Schmoll

12 Tel $+44 /(0) 131 / 651.3608$

13 Fax $+44 /(0) 131 / 650.6564$

14 Email: tim.schmoll@uni-bielefeld.de

15 


\section{Abstract}

The evolutionary origin and the maintenance of extra-pair mating in birds has been a major field of study in the last decades, but no consensus has been reached on the adaptive significance of this behaviour for female birds. The genetic benefit hypothesis proposes that extra-pair sires provide alleles of superior quality and/or better compatibility compared to the social mate, resulting in offspring of higher reproductive value. One frequently adopted approach to test this idea compares the performance of maternal half-siblings in broods with multiple paternity. However, results from such comparisons are inconsistent. Here I discuss the idea that the magnitude of genetic fitness benefits from extra-pair mating depends on the environmental context. Context-dependent genetic effects in maternal half-sibling comparisons have been demonstrated for only five passerine bird species up to date. In none of the studies were the crucial environmental conditions experimentally manipulated and the potentially confounding effects of differential maternal investment in relation to paternity were mostly not accounted for either. A number of high-quality data sets on fitness consequences of extra-pair mating behaviour are available that could be (re-) analysed for context-dependence given relevant gradients of the environment have been recorded and their use is well justified a priori. Such relevant variation may include, for example, the time of breeding in temperate regions, hatching order, but also offspring sex. Primarily, however, experimental approaches are required that systematically and gradually vary fitness-relevant environmental gradients like food availability or parasite abundance and analyse the resulting differential fitness effects while controlling for differential investment. Context-dependence of genetic effects of extrapair mating behaviour may offer an opportunity for reconciling conflicting results from different extra-pair paternity studies within and across species. More generally, it could allow better understanding under which environmental conditions selection may act to maintain a female mating bias towards extra-pair males with potentially far-reaching implications for the ecology and evolution of mating preferences and the maintenance of genetic variation in (sexually) selected traits. 


\section{Keywords}

compatible genes; context-dependence; differential investment; extra-pair paternity; genotypeby-environment interaction; good genes; fitness consequences; half-sibling comparison; multiple mating.

\section{Introduction}

Extra-pair paternity (EPP) arises when female birds engage in extra-pair copulations (EPC) with males other than their social mates, frequently resulting in broods with multiple paternity which contain offspring sired by the social male (within-pair offspring, WPO) and offspring sired by extra-pair males (extra-pair offspring, EPO). A large and solid body of evidence has impressively demonstrated that EPP is the rule rather than the exception in birds (especially in passerines), and a number of synthetic contributions have reviewed this field with its various ramifications over the last two decades (e.g. Westneat et al. 1990; Birkhead and Møller 1992; Petrie and Kempenaers 1998; Griffith et al. 2002; Westneat and Stewart 2003; Akçay and Roughgarden 2007).

As EPP is so widespread and so common and because it must be considered a powerful source of pre- as well as postcopulatory sexual selection, no comprehensive understanding of avian mating systems and sexual selection in birds seems possible without understanding the evolutionary causes and consequences of this phenomenon. However, despite the very substantial research effort in the field, there is still no consensus on a number of fundamental questions related to this topic. For example, there is sustained debate about which sex is actually in control of EPC behaviour and, particularly, about the adaptive significance of extrapair mating behaviour for female birds (e.g. Griffith et al. 2002; Westneat and Stewart 2003; Arnqvist and Kirkpatrick 2005; Griffith 2007; Akçay and Roughgarden 2007; Griffith and Immler 2009). A number of different hypotheses have been put forward to explain why female birds mate extra-pair, which are discussed in more detail in the reviews mentioned above. In this contribution I will focus on the idea that has gained most attention and stimulated the most intense and most controversial debate in the past, i.e. that genetic benefits from a mating bias towards extra-pair sires select for extra-pair mating behaviour in females (for a more general review and discussion of genetic benefit models of mate choice see e.g. Jennions and Petrie 2000; Mays and Hill 2004; Neff and Pitcher 2005).

After briefly introducing the genetic benefit hypothesis of extra-pair mating and the advantages and potential problems of using maternal half-sibling comparisons to test it, I will outline the idea that the magnitude of genetic benefits of extra-pair matings may depend on 
environmental context and illustrate potential consequences for the evolution of female mating preferences and the maintenance of genetic variation for traits under selection. Then I will briefly summarise and review the main results of the few empirical studies that have demonstrated context-dependent genetic effects of extra-pair matings and suggest potential directions for future research in this field. In line with other recent conceptual contributions (e.g. Greenfield and Rodriguez 2004; Bussière et al. 2008; Ingleby et al. 2010), this paper aims at promoting an approach that puts work on sexual selection more explicitly into the ecological context within which it operates.

\section{Genetic benefit hypothesis of extra-pair mating - good and/or compatible alleles}

The principal idea behind the genetic benefits hypothesis is that, by engaging in extra-pair matings, females express a mating preference that is otherwise constrained, for example because social monogamy precludes many females from mating with the few top genetic quality males in a population or because the best social and the best genetic mate for any individual female are not identical. This hypothesis therefore assumes that female birds have a substantial degree of control over extra-pair fertilizations through either pre-copulatory extrapair mate choice and/or cryptic postcopulatory mechanisms that bias paternity in favour of (particular) extra-pair sires. In the following, I will subsume both these possibilities under the term "mating preference" (for extra-pair males), which does therefore not necessarily imply classic precopulatory mate choice. A further assumption of the genetic benefit hypothesis is that extra-pair mating behaviour is costly for females and needs to be balanced by some sort of fitness benefit. This benefit may lie in the higher viability or fecundity and/or sexual attractiveness of offspring sired through EPCs with males that are of higher genetic quality or of better genetic compatibility compared to the respective social mate. The proposed genetic benefits may therefore be assumed to be additive genetic (acquisition of "good alleles") or represent non-additive effects presupposing an interaction of maternal and paternal genotype (acquisition of "compatible alleles" sensu Kempenaers 2007, i.e. broadly defined as alleles that increase fitness contingent on the genetic make-up of the choosing individual). Thus, a mating preference for mates with compatible alleles may, for example, include biasing paternity to maximise offspring heterozygosity, minimise the risk of close inbreeding, or optimise immunogenetic complementarity. Both types of benefits are not mutually exclusive but could also operate in concert. 
113 The most straightforward test of the genetic benefit hypothesis of extra-pair mating is a

114 comparison of the performance of maternal half-siblings from multiply sired broods (Sheldon et 115 al. 1997). Here, potentially confounding, non-genetic effects of a common environment of sire 116 and offspring as well as maternal effects on offspring fitness-related traits are controlled for

117 (but see paragraph on differential maternal investment below). Maternal half-siblings share, by

118 definition, on average half of their maternally inherited nuclear genes and experience the same

119 early environment, including, for example, the same parenting skills of the respective social

120 parents or exposure to the same parasite load in the shared nest. Therefore, any systematic

121 differences in phenotypic traits between the two maternal half-sibships can only be attributed to

122 the differential paternal genetic contribution (differential paternity hereafter) of the respective

123 genetic sires. A consistently superior performance of EPO compared to their WPO maternal

124 half-siblings is thus considered strong evidence in favour of the genetic benefit hypothesis

125 (Sheldon et al. 1997; Griffith et al. 2002). In principal, this statement is true regardless of

126 whether the proposed genetic benefits are assumed to represent additive or non-additive effects 127 (but see Griffith and Immler 2009).

\section{Extra-pair paternity and genetic benefits - inconsistent results}

130 Evidence for a genetic type of benefit based on maternal half-sibling comparisons is rather 131 mixed across studies. Some highly cited landmark studies spectacularly support the genetic 132 benefit hypothesis. For example, in Collared Flycatchers Ficedula albicollis, EPO were in 133 better body condition near fledging compared to their maternal half-siblings (Sheldon et al. 134 1997), and nestling condition has been shown to positively affect recruitment in this species 135 (Lindén et al. 1992). Furthermore, the difference in mean body condition between half-sibships 136 was predicted by the difference in size of an at least partly intersexually selected male ornament 137 of the respective sires (the white forehead patch, Sheldon et al. 1997). In Bluethroats Luscinia 138 svecica, EPO nestlings showed better cellular immunocompetence than their maternal and, 139 notably, also their paternal half-siblings, suggesting not only a genetic benefit from an extra140 pair mating preference, but also an interaction effect of maternal and paternal genotype on 141 offspring immunocompetence (Johnsen et al. 2000; see also Fossøy et al. 2008). Strong support 142 in favour of the genetic benefit hypothesis of extra-pair mating also comes from a study in the 143 Blue Tit Cyanistes caeruleus. Here, EPO sired by non-local extra-pair males showed higher 144 average heterozygosity compared to their maternal half-siblings and individual heterozygosity 145 was positively correlated with a number of fitness-related traits in both sexes (Foerster et al. 
2003). In contrast to these findings, other studies failed to reveal any systematic differences in maternal half-sibling performance, sometimes in the same or in closely related species (e.g. Strohbach et al. 1998; Lubjuhn et al. 1999; Whittingham and Dunn 2001; Schmoll et al. 2003; Edly-Wright et al. 2007; Rosivall et al. 2009; Dunn et al. 2009). Furthermore, application of identical experimental protocols (e.g. the phytohemagglutinin test of cellular immunocompetence) in different species with similar extra-pair mating systems produced mixed results (Johnsen et al. 2000; Kleven and Lifjeld 2004; Kleven et al. 2006; Fossøy et al. 2008; Wilk et al. 2008; Forsman et al. 2008; Butler et al. 2009). The inconsistencies of results across EPP studies may be caused by methodological challenges and/or reflect true and meaningful differences in the respective study systems. In either case, it is important to address this heterogeneity in order to evaluate how reproducible and how generalisable these results may or may not be.

\section{Effect sizes of genetic benefits likely to be small}

The inconsistency of results across EPP studies may be related to the fact that additive genetic fitness benefits from mate choice are likely to be small in general (e.g. Kirkpatrick and Barton 1997; Møller and Alatalo 1999; Arnqvist and Kirkpatrick 2005). Thus, even studies with comparatively large sample sizes may fail to detect any effects of differential paternity on offspring fitness due to a type II statistical error (accepting the null hypothesis when it is wrong), which may contribute to the observed heterogeneity in results across EPP studies. Given small expected effect sizes, the other side of the same coin is that studies actually demonstrating differences in maternal half-sibling performance based on comparatively small samples sizes may be prone to a type I statistical error (rejecting the null hypothesis when it is true), potentially seconded by differential maternal investment in relation to paternity (see below).

Recent conceptual contributions emphasize the potential of non-additive genetic benefits from extra-pair mating (e.g. Kempenaers 2007; Griffith and Immler 2009). For example, a number of studies have reported that EPO were more heterozygous than their WPO maternal half-siblings (e.g. Foerster et al. 2003; Stapleton et al. 2007; Suter et al. 2007; Fossøy et al. 2008; but see Wetzel and Westneat 2009) or that EPO not only outperformed their maternal, but also their paternal half-siblings (Johnsen et al. 2000; Garvin et al. 2006), suggesting non-additive rather than additive genetic benefits of extra-pair matings. However, a recent meta-analytical approach revealed that effect sizes of heterozygosity-fitness correlations are generally positive in sign, but not large either (Chapman et al. 2009). Accordingly, the 
magnitude of non-additive fitness benefits to be potentially obtained through extra-pair mating

181 may be expected to be rather small, too. This may not be the case for all types of non-additive genetic effects, however, for example if extra-pair mating helps preventing fertilisations which would lead to a substantial fitness loss due to pronounced inbreeding (e.g. Keller 1998; Kruuk et al. 2002) or outbreeding (Veen et al. 2001) depression.

\section{Differential maternal investment may confound paternal genetic effects}

187 Selection may favour females with the ability to bias resource allocation in favour of offspring 188 descending from preferred sires (Burley 1986; Møller and Thornhill 1998). If females selectively favour their extra-pair offspring because their sires were of superior genetic quality, superior EPO performance may at least partly be due to maternal rather than paternal genetic effects. Thus, differential maternal investment with respect to paternity may have the potential to confound paternal genetic effects on offspring fitness (Mousseau and Fox 1998; Møller and Thornhill 1998). On the other hand, it can be argued that a biased investment in favour of EPO may make a case for rather than against the genetic benefit hypothesis, since differential investment solely depends on differential paternity (Sheldon 2000). This argumentation seems less straightforward in light of recent studies suggesting that EPO occur earlier in the laying order and, accordingly, in the hatching sequence than their WPO maternal half-siblings, giving them a head start in sibling competition (e.g. Magrath et al. 2009; Ferree et al. 2010). For example, Magrath et al. (2009) not only demonstrated that EPO hatch slightly earlier than WPO, but also that statistically significant differences between maternal half-siblings in morphology and survival until fledging tend to diminish once hatching sequence is statistically controlled for. At present, it is unclear whether females time EPCs to occur early in their laying phase, whether these sequence effects reflect mating effort patterns of social or extra-pair sires, or whether they simply represent a by-product of social or ecological constraints on EPC behaviour (discussed in Magrath et al. 2009). In any case, such effects have the potential to confound paternal genetic effects on offspring fitness for both, additive as well as non-additive genetic benefits, possibly leading to an overestimation of the effects of differential paternity.

\section{Context-dependent genetic benefits of mating preferences and their implications}

210 Another explanation for inconsistent results from maternal half-sibling comparisons may be 211 that the genetic benefits of extra-pair matings vary in magnitude in relation to the prevailing 212 environmental conditions (please note that, while in the compatible alleles model the genetic 213 background of a female may well be seen as an "environment" or a "context" within which 
214 paternal alleles are expressed and with which they may interact, I reserve the use of these terms

215 for extra-genomic components of the environment). Benefits may be large enough to be

216 detectable in some ecological circumstances, but too small or non-existent in others. Such

217 context-dependent genetic effects presuppose temporal and/or spatial variation in the

218 environment - a ubiquitous feature in most natural bird populations. They also presuppose

219 genotypes to differ in how their fitness is affected by variation in the environment, i.e.

220 genotype-by-environment interactions for fitness must be present. If this is not the case, the

221 relative genetic benefit a female may obtain from choosing among different sires is identical

222 across environments (Fig. 1 a, b). However, whenever such genotype-by-environment

223 interactions exist, there is a potential for context-dependent genetic effects to occur (Fig. $1 \mathrm{c}$,

224 d). This refers to sire as well as offspring genotypes in the case of additive genetic effects, but

225 only to offspring genotypes in the case of non-additive genetic effects for which offspring

226 fitness is not normally a function of sire genotype but determined by the interaction of maternal 227 and sire genotype.

228 Two principal cases of genotype-by-environment interactions can be distinguished.

229 First, if fitness reaction norms do not cross and the fitness rank order of genotypes is preserved 230 across the environments that are experienced, context-dependent genetic effects will affect the 231 magnitude of the genetic benefit a female can potentially obtain, although not its sign (Fig. $1 \mathrm{c}$ ).

232 Single best male genotypes on the level of the population (in case of additive genetic effects) or 233 most compatible male genotypes on the level of the individual female (in case of non-additive 234 genetic effects) may exist and they are transient across these environments. Second, if fitness 235 reaction norms cross and the fitness rank order of genotypes is not preserved across the 236 environments that are experienced, context-dependent genetic effects will not only affect the 237 magnitude of the genetic benefit a female may obtain, but also its sign, rendering preferences 238 for particular sire genotypes adaptive in some of these environments, but not in others (Fig. $1 \mathrm{~d}$, 239 also termed ecological cross-over). Here, no single best male genotypes on either the level of 240 the population or the level of the individual female do exist. Indeed, the terms "good alleles" or 241 "compatible alleles" in reference to any particular male genotype do not make sense under this 242 scenario. In both cases, however, context-dependent genetic effects suggest selection on female 243 mating preferences to vary across environments, which has interesting implications for the 244 evolution of mating preferences and the maintenance of genetic variation in traits that are under sexual selection.

If relevant gradients of the environment that offspring will experience are fairly well 247 predictable, we may expect females to show phenotypically plastic instead of static mating 
preferences (discussed in Qvarnström 2001). In the case of non-crossing fitness reaction norms, they may be selected to balancing direct costs of choice against expected genetic rewards and hence express any given preference more or less strongly depending on environmental variation. In the case of additive genetic effects, the strength of sexual selection on preferred male traits (secondary sexual characters and genetically correlated traits) will then vary accordingly and episodes of relaxed selection could slow down the depletion of genetic variance in these traits or even contribute to its maintenance by allowing more time for deleterious mutations to occur. In the case of ecological cross-over, plastic preferences would need to be reversed to be adaptive and would hence directly support maintenance of genetic variation in male traits. If the environmental conditions that offspring will experience are largely unpredictable, however, females may not benefit at all from expressing mating preferences for any particular sire genotype. For example, in the case of ecological cross-over in fitness, females have no means to evaluate the relative genetic quality of potential mates and they may rather opt for genetic bet-hedging, mate multiply and thereby sample a number of different sires in order to increase the within-cohort genetic diversity of their offspring (see Yasui 1998 for more background on this argument and Schmoll et al. 2007 for an application to extra-pair mating behaviour in birds).

Context-dependent genetic benefits from mate choice in general have been shown in a range of taxa including insects (Jia and Greenfield 1997), anurans (Welch 2003; Sheldon et al. 2003), and mammals (Mills et al. 2007). Furthermore, context-dependent genetic benefits from mate choice may be inferred from studies demonstrating genotype-by-environment interactions on the expression of male sexual signal traits under directional intersexual selection (e.g. Qvarnström 1999; Jia et al. 2000; David et al. 2000; Danielson-François et al. 2006; see also Greenfield and Rodriguez 2004). In the following paragraph, I will apply the idea of contextdependent genetic effects to extra-pair mating behaviour in birds and briefly review the few studies that have suggested such effects up to date.

\section{Context-dependent genetic effects of extra-pair mating}

276 In order to demonstrate context-dependent additive genetic effects of extra-pair matings, it is 277 necessary to test for a two-way interaction effect of differential paternity and the focal environmental variable on offspring traits, i.e. EPO and WPO "genotypes" are predicted to react in a different manner to different environmental conditions. In a purely operational view, the same is true for non-additive genetic effects, although conceptually, a three-way interaction 
magnitude of the fitness effects of the interaction between maternal and paternal genotypes depends on the environmental context.

As far as I am aware, only five studies - relating to five different species - have demonstrated context-dependent genetic effects when testing for maternal half-sibling performance. In the socially monogamous Coal Tit Periparus ater EPO had a higher probability of local recruitment into the breeding population compared to their WPO maternal half-siblings only when they originated from late (i.e. second) broods, but not when they originated from early (i.e. first) broods (Schmoll et al. 2005). Recruitment probability in general was significantly reduced in late broods, such that the superior performance of EPO coincides with environmental conditions that are stressful compared to those in early broods (Schmoll et al. 2005). First-year reproductive performance was affected in a similar way, reflecting the differential recruitment patterns (Schmoll et al. 2005). No context-dependent effects were apparent in the same study population in an analysis of fitness-related traits that are expressed beyond recruitment (Schmoll et al. 2009).

In the socially monogamous Common Yellowthroat Geothlypis trichas, EPO mounted a stronger cellular immune response than their WPO maternal half-siblings only in the colder of two study years, but not in the warmer one (Garvin et al. 2006). Low ambient temperatures negatively affect offspring immunocompetence (directly and/or indirectly e.g. via food abundance) such that superior performance of EPO coincides with environmental conditions that are relatively stressful (Garvin et al. 2006).

In the socially polygynous Red Bishop Euplectes orix, WPO were found to be more immunocompetent than their EPO maternal half-siblings only in the hotter of two study years, but not in the cooler one (Edler and Friedl 2008). Compared to the yellowthroat study (Garvin et al. 2006), the pattern thus appears reversed with respect to both, the relative genetic quality of maternal half-siblings and the effect of ambient temperature as a key environmental variable. Hotter seasons, however, are likely to provide less favourable breeding conditions in this African species due to a lack of nestling food and increased heat stress (Edler and Friedl 2008). The fact that WPO instead of EPO perform better under such stressful conditions may be explained by the polygynous mating system of this species. Females paired to highly attractive and therefore more strongly polygynous males face an increased risk that their social mate runs out of sperm and seem to use EPC as a means to insure themselves against their high-quality social mates being temporarily infertile. Consequently, mainly less attractive males of presumably lower genetic quality may be successful in siring EPO (Friedl and Klump 2005; Edler and Friedl 2008). In this mating system, it thus seem to be WPO, not EPO, which are of 
higher genetic quality, so that the superior performance of offspring of relatively better genetic quality coincides with relatively stressful environmental conditions (Edler and Friedl 2008).

In the socially monogamous Tree Swallow Tachycineta bicolor, EPO had longer ninth primary feathers at nestling day 16 than their maternal half-siblings only when natural parasite abundance was low and when they had hatched early relative to their WPO maternal halfsiblings (O'Brien and Dawson 2007). The difference in ninth primary length at a particular developmental stage (i.e. near fledging) is seen as reflecting a genetic benefit of extra-pair mating, because nestling wing length predicts time of fledging and wing length at fledging is positively related to recruitment probability in the study species (discussed in O'Brien and Dawson 2007). This study differs from the previous ones not only in that it considers, conceptually, a three-way interaction (the effects of differential paternity were dependent on the interaction of two environmental dimensions, parasite abundance and relative hatch order). In contrast to the former studies, it was also in relatively favourable, not stressful, conditions that EPO have differed from their WPO half-siblings (O'Brien and Dawson 2007).

Finally, in the predominantly socially monogamous House Wren Troglodytes aedon WPO were more immunocompetent than their EPO maternal-half-siblings in two out of three study years, but the publication did not give reference as to whether these differences were related to relevant variation in (the quality of) the environment (Forsman et al. 2008).

\section{Poor environmental quality - revealing or concealing paternal genetic effects?}

336 The studies summarised above differ in how they see the role of environmental quality in determining the extent of genetic variation that is expressed in offspring phenotypes. Three out of the five studies that have demonstrated context-dependent genetic effects show a pattern where only comparatively poor environments seem to reveal genetic variation. An explanation for this could be that under beneficial environmental conditions all offspring may perform relatively well irrespective, to some degree, of their genetic quality (i.e. of being sired withinpair or extra-pair). Beneficial environments may thus have the potential to mask genetic variation in fitness-related traits, and, as a consequence, it would be difficult to demonstrate the differences in maternal half-sibling performance predicted by the genetic benefit hypothesis. This is particularly relevant when taking into account that the magnitude of genetic benefits of mate choice must be expected to be small in general (see above). In contrast, comparatively stressful conditions where essential resources are limited may reveal this genetic variation and it is only then that the small genetic differences between maternal half-siblings are reflected in their phenotypic performance and become detectable with limited sample sizes. Along similar 
lines, inbreeding depression is generally (although not universally) more pronounced under stressful conditions across a wide range of taxa according to a recent meta-analysis (Fox and Reed 2011). As an example in birds, Keller et al. (2002) report a case of inbreeding-byenvironment interaction in the Cactus Finch Geospiza scandens. For example, inbreeding depression for adult survival was most severe under unfavourable conditions (i.e. dry climate and high population densities), but substantially less pronounced under a range of other conditions (Keller et al. 2002). Similarly, nestling survival in great tits Parus major was negatively affected by parental genetic similarity only late in the season when food resources are likely to be more restricted (Van de Casteele et al. 2003). Thus in both examples inbred versus outbred genotypes differed in their response to varying conditions with only stressful environments reflecting the existing genetic variation in the phenotype (see also Marr et al. 2006; Szulkin and Sheldon 2007).

In contrast to the former work, the Tree Swallow study by O'Brien et al. (2007) found that it is in relatively favourable conditions when half-siblings differ in performance. The difference between this study and the previous ones may be the type of focal trait considered or the type of genetic effect supposed to create the observed differential half-sibling performance. In the case of a morphological character such as feather length, the underlying type of effect is likely to be additive genetic and the full range of existing genetic variation may only be expressed in the phenotype under favourable conditions, when individual genotypes can max out their genetic potential (Hoffmann and Merilä 1999; see also Qvarnström 1999 reporting higher heritability of a sexually selected feather ornament under beneficial conditions). The other studies did not address differences in morphological characters but traits that seem more closely related to fitness. In contrast to morphometric traits, the phenotypic expression of genetic variation for such traits does not seem to be promoted by favourable conditions (Charmantier and Garant 2005). Neither do differences in these traits necessarily reflect additive genetic benefits of extra-pair matings. For example, a significantly better performance of EPO not only in maternal, but also in paternal half-sibling comparisons reported in Garvin et al. (2006) indicates a non-additive type of benefit in this case.

\section{Conclusions}

In conclusion, only five empirical studies have suggested context-dependent genetic effects of extra-pair mating in birds up to date. None of these studies, however, has experimentally manipulated the focal environmental dimensions and hence results are open for alternative 
general and hatching sequence in particular. This is problematic because differential maternal investment in favour of EPO may not only confound effects of differential paternity in general, but lead to effects similar to those predicted from the context-dependence hypothesis. Finally, it is also mostly not clear, how variation in offspring quality traits relates to variation in fitness and how variation in the environmental variables highlighted in these studies affects offspring quality traits (with year effects being a case in point). Thus evidence for context-dependent genetic benefits from extra-pair matings in birds is suggestive rather than conclusive at present and it is unclear how important and how widespread context-dependent genetic effects of extrapair mating may actually be and how consistently specific (e. g. high-stress versus low-stress) environments may affect the context-dependent expression of genetic variation.

\section{Perspectives}

Studies addressing the genetic benefits of extra-pair matings by comparing maternal halfsiblings have generally used a range of different offspring quality traits and the few studies that have demonstrated context-dependent effects have likewise picked a number of different environmental variables to test for interactions with differential paternity (see above). The availability of many such potential response variables and, in particular, the availability of many potentially important predictor variables (i.e. environmental dimensions) harbours the risk of revealing spurious associations when testing for two-way (or even higher-order) interactions with differential paternity. Obviously, focal offspring quality traits must exhibit a verifiably close relationship with fitness, preferably as demonstrated in the very study population, to allow meaningful inference regarding the fitness consequences of extra-pair mating behaviour (frequently this relationship is assumed rather than established). Furthermore, to qualify as a "relevant" dimension of environmental quality, any candidate variable should predictably affect the focal offspring quality trait, preferably in a manner that is also understood mechanistically in some detail. Which offspring quality traits may be regarded and which particular dimension of the environment may be considered "relevant" will ultimately depend on the particular study system, but response and predictor variable(s) should be carefully chosen and well defined a priori for both, the observational as well as the experimental approaches outlined below.

A number of high-quality data sets on maternal half-sibling performance is meanwhile available (or being collected) and may frequently have been sampled across different environmental contexts. These data could be (re-) analysed while explicitly considering relevant environmental variation. Studies that have failed to establish the predicted differences 
in maternal half-sibling performance may then find that under some circumstances these effects are detectable (note that there was no support for an "overall" (i.e. main) effect of differential paternity in some of the studies that demonstrated context-dependence, cf. Fig. 1 in Schmoll et al. 2005). However, also studies that have shown differences in maternal half-sibling performance may benefit by allowing a deeper understanding when taking ecology into account, for example if an overall effect of differential paternity largely relates to particular sub-samples in the data sets (but see discussion on the risk of spurious findings above). At this stage, reporting a lack of evidence for context-dependence is also of considerable interest (given sample sizes are reasonably large), to avoid publication bias and obtain a balanced view on how common such effects may or may not be in natural populations.

As an example, in many bird populations in temperate regions, environmental conditions deteriorate predictably and substantially over the breeding season while laying and/or hatching date are recorded routinely in many studies. They could thus serve retrospectively as a proxy for ecological contexts of varying quality to compare the relative performance of maternal half-siblings against, even if more meaningful data like quantitative estimates of food abundance are not available. Similarly, available weather data combined with longterm data sets could identify key meteorological variables affecting fitness-related traits and these gradients of environmental variation could be used to test for interations with differential paternity.

Instead of considering laying or hatching order primarily a potentially confounding factor when analysing maternal half-sibling performance (see above), it could also be seen as reflecting yet another relevant dimension of the natural environment. There is evidence that hatching order directly affects early survival prospects in many altricial bird species through asymmetrical sibling competition, particularly when hatching asynchrony is pronounced (Magrath 1990; see also Magrath et al. 2009). Thus, once hatching sequence has been recorded in order to control its effects, testing for differential paternity-by-hatching sequence interactions may also represent a valuable option for testing the context-dependence hypothesis.

Different from the truly ecological variables discussed above, offspring sex may also be regarded a relevant dimension of environmental context. Fitness effects of particular alleles may be sex-dependent, for example due to sexually antagonistic selection resulting from intralocus sexual conflict (Bonduriansky and Chenoweth 2009). Such sexually antagonistic fitness variation could render effects of paternal genetic contribution sex-dependent, too. Thus it may be worthwhile considering offspring sex as an (intragenomic) dimension of the environment within which paternal alleles are expressed, and test for differential paternity-by- 
offspring sex effects on fitness traits in both, observational and experimental approaches (see below). Of course, the magnitude of such effects may again depend on external dimensions of the environment, which may require testing for three-way interactions of differential paternity, offspring sex and quality of the environment. If the effects of differential paternity were indeed sex-dependent or even sexually antagonistic, it would be adaptive for females to adjust sex allocation in relation to paternity, because only then would they be able to obtain a (maximum) net genetic benefit from extra-pair mating. For example, male extra-pair offspring may inherit alleles from their attractive (i.e. extra-pair) fathers that will make themselves more attractive as extra-pair sires while the same alleles may negatively affect the fitness prospects and thus the reproductive value of female offspring. In general, there is good evidence for the ability of female birds to facultatively bias offspring sex ratio, for example in relation to the sexual attractiveness (e.g. Ellegren et al. 1996) or the genetic compatibility (e.g. Pryke and Griffith 2009) of their social mates. However, in the context of extra-pair mating behaviour, evidence for facultative sex allocation in relation to paternity is rather weak. Only a single study has unequivocally demonstrated the predicted sex ratio bias towards males in extra-pair offspring (Johnson et al. 2009), while many others tried, but failed (e.g. Sheldon and Ellegren 1996; Leech et al. 2001; Dietrich-Bischoff et al. 2006). Thus, if differential paternity was indeed sexually antagonistic in its effects, fitness gains realised via the advantaged sex would possibly have to exceed the fitness costs incurred by the disadvantaged sex to render extra-pair matings adaptive.

Most importantly, however, experimental approaches are needed that systematically manipulate relevant environmental contexts and subsequently test for differential paternity-bytreatment effects. If genetic benefits are assumed to be apparent more clearly under relatively poor conditions, the goal is provoking genetic effects by deteriorating environmental contexts to a degree that provides stressful conditions that could be encountered by the study population (at least from time to time), but that is still acceptable from an ethical point of view (and does also not lead to an overwhelmingly detrimental environmental effect which would also blur differences between genotypes). We may then predict a significant interaction between paternity and experimental treatment with differences between half-siblings being more pronounced under relatively poor conditions. Ideally, any treatment would create more than just two experimental environments to better understand the predicted differential reaction norm trajectories of offspring quality traits (which may not necessarily be linear as assumed in Fig. 1 for the sake of clarity). As expected effect sizes are small, such experiments need to be carried out on a larger scale that maximises the number replicates (i.e. broods with multiple paternity). 
Given that differential maternal investment with respect to paternity may lead to the same type of context-dependent effects as predicted by the genetic benefit hypothesis, future studies need to control such effects in general and hatching order in particular.

In the field, brood size manipulation experiments are one straightforward option to manipulate the degree of sibling competition and thus resource availability. Cross-fostering designs may then easily be tailored to create a range of experimental environments of different quality. Furthermore, by separating offspring from their natural parents at an early stage through cross-fostering of entire (half-) sibships, potential post-hatching effects of maternal or paternal differential allocation in relation to paternity could be controlled. Manipulation of parasite prevalence and/or abundance or nest temperature regimes or enforcing replacement clutches while taking advantage of naturally deteriorating conditions in seasonal environments offer further opportunities depending on the biology of the focal species.

In order to unequivocally demonstrate genetic benefits of female mating preferences, it is necessary to allocate paternity randomly to a focal female's offspring, raise her progeny under identical environmental conditions and then test for differences in fitness between maternal half-sibships descending from preferred versus less preferred sires. This is comparatively easily achieved in laboratory studies of externally fertilising species by means of split-clutch in-vitro fertilisations (e.g. Barber et al. 2001; Welch 2003) and feasible to some degree within captive (semi-natural) populations of certain internally fertilising species (e.g. Petrie 1994). However, the use of artificial insemination techniques in laboratory populations would offer interesting perspectives here, too. Such systems would not only exclude differential maternal investment, but also allow for a much better control and resolution of the experimental environments. One drawback here is that in the few established model species such as the zebra finch, EPP may play only a minor role in natural populations (Griffith et al. 2010).

As the magnitude of the genetic benefits a female may obtain from extra-pair mating is expected to be small (see above), comparatively large sample sizes will normally be required to demonstrate them. When analysing the fitness consequences of extra-pair mating, a replicate typically consists of a brood with multiple paternity and it may thus be challenging to achieve substantial samples, especially in species with relatively low frequencies of EPP. Properly controlling potentially confounding effects of differential maternal investment (see above) makes this an even more difficult enterprise. However, in species where EPO have been unequivocally shown to be more heterozygous than their WPO maternal half-siblings (see above), a shortcut may be testing for the context-dependence of the predicted heterozygosityfitness correlations in the study population/study species instead of testing the context- 
dependence of the fitness effects of differential paternity directly. Similar to context-dependent effects of (close) inbreeding discussed above, heterozygosity-fitness correlations may vary in their strength across environments of different quality, giving rise to heterozygosity-byenvironment interactions (for an interesting example in anurans see Lesbarrères et al. 2005). This approach would not only allow making use of (much) larger samples by also including offspring from broods without multiple paternity (in observational as well as experimental studies). As we can expect substantial random variation in the degree of individual heterozygosity also within each of the two groups of maternal half-siblings (i.e. WPO and EPO), it might also provide a means to efficiently control differential maternal investment, because significant heterozygosity-fitness correlations as well as heterozygosity-byenvironment interactions within these groups cannot be confounded by differential maternal investment in relation to paternity.

Context-dependent genetic benefits imply that it would be adaptive to express costly mating preferences in a phenotypically plastic manner, depending on the expected net benefit within a given environment (Qvarnström 2001; Welch 2003) and there are remarkable examples of adaptive phenotypic plasticity in female mate choice in birds (e.g. Qvarnström et al. 2000; Chaine and Lyon 2008). This flexibility presupposes the ability of females to evaluate the specific quality of the environment that their offspring are likely to experience, which should not pose a major problem in seasonal environments that may vary predictably in quality (see above). Assuming extra-pair matings to be costly, we may thus predict adaptive phenotypic plasticity in female propensity to engage in extra-pair matings. For example, in the Coal Tit population referred to above, the frequency of EPP was substantially higher in second broods (relatively stressful environment) compared to first broods (relatively beneficial environment, Dietrich et al. 2004). This pattern is compatible with a plastic female response in relation to differential environmental conditions, although other explanations may seem more likely (for example a better availability of extra-pair mating opportunities with preferred sires, Dietrich et al. 2004). Nevertheless, comparing the frequency of EPP against the magnitude of genetic benefits (i.e. the difference in half-sibling performance) across different environments (within as well as across populations) may represent a first step to elucidate this idea further.

If context-dependent genetic effects could be demonstrated in a robust and repeatable manner, it may be of interest to determine how frequently environmental contexts arise that allow females to realise a net genetic fitness benefit by mating extra-pair and thus maintain selection for this behaviour in the long run. Analysis of long-term data sets - where available - 
may help to evaluate this and could possibly be used to parameterise models that address the maintenance of mating preferences for extra-pair sires in heterogeneous environments.

This article has focused on how variation in environmental quality may affect the phenotypic expression of the predicted, genetically based differences between EPO and WPO maternal half-siblings, assuming that genotype fitness ranks are maintained across environments (i.e. non-crossing reaction norms as illustrated in Fig. 1c). However, different environments as opposed to environments of different quality (for example in terms of the prevalence of different types of parasites) may also reflect relevant environmental heterogeneity and ecological cross-over of reaction norms in fitness-related traits has been demonstrated in other taxa (e.g. Jia and Greenfield 1997; Welch 2003; Mills et al. 2007) and may also be considered.

The idea of a context-dependence of genetic benefits of extra-pair matings may offer one possible approach for reconciling mixed results from different EPP studies and may thus contribute to resolving the longstanding puzzle why female birds mate extra-pair so frequently. More generally, it may allow understanding under which environmental conditions selection will act to maintain a female mating bias towards extra-pair males. This has potentially farreaching implications for the ecology and evolution of female mating preferences, the maintenance of genetic variation in (sexually) selected traits and possibly the co-evolution of male sexual signals and female mating preferences. Taking into consideration that evidence from other taxa also suggests that context-dependence of genetic benefits of mate choice may be of considerable importance, I conclude that context-dependent genetic effects of mate choice in birds deserve more attention in general and in the context of extra-pair mating in particular.

\section{Acknowledgments}

Thanks to Klaus Reinhold, Peter Korsten and Verena Dietrich-Bischoff who commented on earlier drafts of this manuscript. Thomas Friedl and an anonymous reviewer also provided helpful comments.

\section{References}

Akçay E, Roughgarden J (2007) Extra-pair paternity in birds: review of the genetic benefits. Evol Ecol Res 9:855-868

\section{Arnqvist G, Kirkpatrick M (2005) The evolution of infidelity in socially monogamous} passerines: The strength of direct and indirect selection on extrapair copulation behavior in females. Am Nat 165:S26-S37 
Barber I, Arnott SA, Braithwaite VA, Andrew J, Huntingford FA (2001) Indirect fitness consequences of mate choice in sticklebacks: offspring of brighter males grow slowly but resist parasitic infections. Proc R Soc Lond B 268:71-76

Birkhead TR, Møller AP (1992) Sperm competition in birds: evolutionary causes and consequences. Academic Press, New York

Bonduriansky R, Chenoweth SF (2009) Intralocus sexual conflict. Trends Ecol Evol 24:280288

Burley N (1986) Sexual selection for aesthetic traits in species with biparental care. Am Nat $127: 415-445$

Bussière LF, Hunt J, Stolting KN, Jennions MD, Brooks R (2008) Mate choice for genetic quality when environments vary: suggestions for empirical progress. Genetica 134:6978

Butler MW, Garvin JC, Wheelwright NT, Freeman-Gallant CR (2009) Ambient temperature, but not paternity, is associated with immune response in Savannah Sparrows (Passerculus sandwichensis). Auk 126:536-542

Chaine AS, Lyon BE (2008) Adaptive plasticity in female mate choice dampens sexual selection on male ornaments in the lark bunting. Science 319:459-462

Chapman JR, Nakagawa S, Coltman DW, Slate J, Sheldon BC (2009) A quantitative review of heterozygosity-fitness correlations in animal populations. Mol Ecol 18:2746-2765

Charmantier A, Garant D (2005) Environmental quality and evolutionary potential: lessons from wild populations. Proc R Soc Lond B 272:1415-1425

Danielson-François AM, Kelly JK, Greenfield MD (2006) Genotype x environment interaction for male attractiveness in an acoustic moth: evidence for plasticity and canalization. $\mathbf{J}$ Evol Biol 19:532-542

David P, Bjorksten T, Fowler K, Pomiankowski A (2000) Condition-dependent signalling of genetic variation in stalk- eyed flies. Nature 406:186-188

Dietrich-Bischoff V, Schmoll T, Winkel W, Krackow S, Lubjuhn T (2006) Extra-pair paternity, offspring mortality and offspring sex ratio in the socially monogamous coal tit (Parus ater). Behav Ecol Sociobiol 60:563-571

Dietrich V, Schmoll T, Winkel W, Epplen JT, Lubjuhn T (2004) Pair identity - an important factor concerning variation in extra-pair paternity in the coal tit (Parus ater). Behaviour 141:817-835

Dunn PO, Lifjeld JT, Whittingham LA (2009) Multiple paternity and offspring quality in tree swallows. Behav Ecol Sociobiol 63:911-922 
Edler R, Friedl TWP (2008) Within-pair young are more immunocompetent than extrapair young in mixed-paternity broods of the red bishop. Anim Behav 75:391-401

Edly-Wright C, Schwagmeyer PL, Parker PG, Mock DW (2007) Genetic similarity of mates, offspring health and extrapair fertilization in house sparrows. Anim Behav 73:367-378

Ellegren H, Gustafsson L, Sheldon BC (1996) Sex ratio adjustment in relation to paternal attractiveness in a wild bird population. Proc Natl Acad Sci USA 93:11723-11728

Ferree ED, Dickinson J, Rendell W, Stern C, Porter S (2010) Hatching order explains an extrapair chick advantage in western bluebirds. Behav Ecol 21:802-807

Foerster K, Delhey K, Johnsen A, Lifjeld JT, Kempenaers B (2003) Females increase offspring heterozygosity and fitness through extra-pair matings. Nature 425:714-717

Forsman AM, Vogel LA, Sakaluk SK, Johnson BG, Masters BS, Johnson LS, Thompson CF (2008) Female house wrens (Troglodytes aedon) increase the size, but not immunocompetence, of their offspring through extra-pair mating. Mol Ecol 17:36973706

Fossøy F, Johnsen A, Lifjeld JT (2008) Multiple genetic benefits of female promiscuity in a socially monogamous passerine. Evolution 62:145-156

Fox CW, Reed DH (2011) Inbreeding depression increases with environmental stress: an experimental study and meta-analysis. Evolution 65:246-258

Friedl TWP, Klump GM (2005) Extrapair fertilizations in red bishops (Euplectes orix): Do females follow conditional extrapair strategies? Auk 122:57-70

Garvin JC, Abroe B, Pedersen MC, Dunn PO, Whittingham LA (2006) Immune response of nestling warblers varies with extra-pair paternity and temperature. Mol Ecol 15:38333840

Greenfield MD, Rodriguez RL (2004) Genotype-environment interaction and the reliability of mating signals. Anim Behav 68:1461-1468

Griffith SC (2007) The evolution of infidelity in socially monogamous passerines: Neglected components of direct and indirect selection. Am Nat 169:274-281

Griffith SC, Holleley CE, Mariette MM, Pryke SR, Svedin N (2010) Low level of extrapair parentage in wild zebra finches. Anim Behav 79:261-264

Griffith SC, Immler S (2009) Female infidelity and genetic compatibility in birds: the role of the genetically loaded raffle in understanding the function of extrapair paternity. $\mathrm{J}$ Avian Biol 40:97-101

Griffith SC, Owens IPF, Thuman KA (2002) Extra pair paternity in birds: a review of interspecific variation and adaptive function. Mol Ecol 11:2195-2212 
Hoffmann AA, Merilä J (1999) Heritable variation and evolution under favourable and unfavourable conditions. Trends Ecol Evol 14:96-101

Ingleby FC, Hunt J, Hosken DJ (2010) The role of genotype-by-environment interactions in sexual selection. J Evol Biol 23:2031-2045

Jennions MD, Petrie M (2000) Why do females mate multiply? A review of the genetic benefits. Biol Rev 75:21-64

Jia FY, Greenfield MD (1997) When are good genes good? Variable outcomes of female choice in wax moths. Proc R Soc Lond B 264:1057-1063

Jia FY, Greenfield MD, Collins RD (2000) Genetic variance of sexually selected traits in waxmoths: Maintenance by genotype x environment interaction. Evolution 54:953-967

Johnsen A, Andersen V, Sunding C, Lifjeld JT (2000) Female bluethroats enhance offspring immunocompetence through extra-pair copulations. Nature 406:296-299

Johnson LS, Thompson CF, Sakaluk SK, Neuhäuser M, Johnson BGP, Soukup SS, Forsythe SJ, Masters BS (2009) Extra-pair young in house wren broods are more likely to be male than female. Proc R Soc Lond B 276:2285-2289

Keller LF (1998) Inbreeding and its fitness effects in an insular population of song sparrows (Melospiza melodia). Evolution 52:240-250

Keller LF, Grant PR, Grant BR, Petren K (2002) Environmental conditions affect the magnitude of inbreeding depression in survival of Darwin's finches. Evolution 56:12291239

Kempenaers B (2007) Mate choice and genetic quality: A review of the heterozygosity theory. Adv Stud Behav 37:189-278

Kirkpatrick M, Barton NH (1997) The strength of indirect selection on female mating preferences. Proc Natl Acad Sci USA 94:1282-1286

Kleven O, Jacobsen F, Izadnegahdar R, Robertson RJ, Lifjeld JT (2006) No evidence of paternal genetic contribution to nestling cell-mediated immunity in the North American barn swallow. Anim Behav 71:839-845

Kleven O, Lifjeld JT (2004) Extra-pair paternity and offspring immunocompetence in the reed bunting (Emberiza schoeniclus). Anim Behav 68:283-289

Kruuk LEB, Sheldon BC, Merilä J (2002) Severe inbreeding depression in collared flycatchers (Ficedula albicollis). Proc R Soc Lond B 269:1581-1589

Leech DI, Hartley IR, Stewart IRK, Griffith SC, Burke T (2001) No effect of parental quality or extrapair paternity on brood sex ratio in the blue tit (Parus caeruleus). Behav Ecol 12:674-680 
Lesbarrères D, Primmer CR, Laurila A, Merilä J (2005) Environmental and population dependency of genetic variability-fitness correlations in Rana temporaria. Mol Ecol $14: 311-323$

Lindén M, Gustafsson L, Pärt T (1992) Selection on fledging mass in collared flycatchers and great tits. Ecology 73:336-343

Lubjuhn T, Strohbach S, Brün J, Gerken T, Epplen JT (1999) Extra-pair paternity in great tits (Parus major) - A long term study. Behaviour 136:1157-1172

Magrath MJL, Vedder O, van der Velde M, Komdeur J (2009) Maternal Effects Contribute to the Superior Performance of Extra-Pair Offspring. Curr Biol 19:792-797

Magrath RD (1990) Hatching asynchrony in altricial birds. Biol Rev 65:587-622

Marr AB, Arcese P, Hochachka WM, Reid JM, Keller LF (2006) Interactive effects of environmental stress and inbreeding on reproductive traits in a wild bird population. $\mathrm{J}$ Anim Ecol 75:1406-1415

Mays HL, Hill GE (2004) Choosing mates: good genes versus genes that are a good fit. Trends Ecol Evol 19:554-559

Mills SC, Alatalo RV, Koskela E, Mappes J, Mappes T, Oksanen TA (2007) Signal reliability compromised by genotype-by-environment interaction and potential mechanisms for its preservation. Evolution 61:1748-1757

Møller AP, Alatalo RV (1999) Good-genes effects in sexual selection. Proc R Soc Lond B 266:85-91

Møller AP, Thornhill R (1998) Male parental care, differential parental investment by females and sexual selection. Anim Behav 55:1507-1515

Mousseau TA, Fox CW (1998) The adaptive significance of maternal effects. Trends Ecol Evol 13:403-407

Neff BD, Pitcher TE (2005) Genetic quality and sexual selection: an integrated framework for good genes and compatible genes. Mol Ecol 14:19-38

O'Brien EL, Dawson RD (2007) Context-dependent genetic benefits of extra-pair mate choice in a socially monogamous passerine. Behav Ecol Sociobiol 61:775-782

Petrie M (1994) Improved Growth and Survival of Offspring of Peacocks with More Elaborate Trains. Nature 371:598-599

Petrie M, Kempenaers B (1998) Extra-pair paternity in birds: explaining variation between species and populations. Trends Ecol Evol 13:52-58

Pryke SR, Griffith SC (2009) Genetic Incompatibility Drives Sex Allocation and Maternal Investment in a Polymorphic Finch. Science 323:1605-1607 
Qvarnström A (1999) Genotype-by-environment interactions in the determination of the size of a secondary sexual character in the collared flycatcher (Ficedula albicollis). Evolution 53:1564-1572

Qvarnström A (2001) Context-dependent genetic benefits from mate choice. Trends Ecol Evol $16: 5-7$

Qvarnström A, Pärt T, Sheldon BC (2000) Adaptive plasticity in mate preference linked to differences in reproductive effort. Nature 405:344-347

Rosivall B, Szöllösi E, Hasselquist D, Török J (2009) Effects of extrapair paternity and sex on nestling growth and condition in the collared flycatcher, Ficedula albicollis. Anim Behav 77:611-617

Schmoll T, Dietrich V, Winkel W, Epplen JT, Lubjuhn T (2003) Long-term fitness consequences of female extra-pair matings in a socially monogamous passerine. Proc $\mathrm{R}$ Soc Lond B 270:259-264

Schmoll T, Dietrich V, Winkel W, Epplen JT, Schurr F, Lubjuhn T (2005) Paternal genetic effects on offspring fitness are context dependent within the extrapair mating system of a socially monogamous passerine. Evolution 59:645-657

Schmoll T, Schurr FM, Winkel W, Epplen JT, Lubjuhn T (2007) Polyandry in coal tits Parus ater: fitness consequences of putting eggs into multiple genetic baskets. J Evol Biol 20:1115-1125

Schmoll T, Schurr FM, Winkel W, Epplen JT, Lubjuhn T (2009) Lifespan, lifetime reproductive performance and paternity loss of within-pair and extra-pair offspring in the coal tit Periparus ater. Proc R Soc Lond B 276:337-345

Sheldon BC (2000) Differential allocation: tests, mechanisms and implications. Trends Ecol Evol 15:397-402

Sheldon BC, Arponen H, Laurila A, Crochet PA, Merilä J (2003) Sire coloration influences offspring survival under predation risk in the moorfrog. J Evol Biol 16:1288-1295

Sheldon BC, Ellegren H (1996) Offspring sex and paternity in the collared flycatcher. Proc R Soc Lond. B 263:1017-1021

Sheldon BC, Merilä J, Qvarnström A, Gustafsson L, Ellegren H (1997) Paternal genetic contribution to offspring condition predicted by size of male secondary sexual character. Proc R Soc Lond B 264:297-302

Stapleton MK, Kleven O, Lifjeld JT, Robertson RJ (2007) Female tree swallows (Tachycineta bicolor) increase offspring heterozygosity through extrapair mating. Behav Ecol Sociobiol 61:1725-1733 
Strohbach S, Curio E, Bathen A, Epplen JT, Lubjuhn T (1998) Extrapair paternity in the great tit (Parus major): a test of the "good genes" hypothesis. Behav Ecol 9:388-396

Suter SM, Keiser M, Feignoux R, Meyer DR (2007) Reed bunting females increase fitness through extra-pair mating with genetically dissimilar males. Proc R Soc Lond B $274: 2865-2871$

Szulkin M, Sheldon BC (2007) The Environmental Dependence of Inbreeding Depression in a Wild Bird Population. PLoS ONE 2

Van de Casteele T, Galbusera P, Schenck T, Matthysen E (2003) Seasonal and lifetime reproductive consequences of inbreeding in the great tit Parus major. Behav Ecol $14: 165-174$

Veen T, Borge T, Griffith SC, Saetre GP, Bures S, Gustafsson L, Sheldon BC (2001) Hybridization and adaptive mate choice in flycatchers. Nature 411:45-50

Welch AM (2003) Genetic benefits of a female mating preference in gray tree frogs are context-dependent. Evolution 57:883-893

Westneat DF, Sherman PW, Morton WL (1990) The ecology and evolution of extra-pair copulations in birds. In: Power DM (ed) Curr Ornitol, vol 7. Plenum Press, New York, pp 331-369

Westneat DF, Stewart IRK (2003) Extra-Pair Paternity in Birds: Causes, Correlates, and Conflict. Ann Rev Ecol Evol Syst 34:365-396

Wetzel DP, Westneat DF (2009) Heterozygosity and extra-pair paternity: biased tests result from the use of shared markers. Mol Ecol 18:2010-2021

Whittingham LA, Dunn PO (2001) Survival of extrapair and within-pair young in tree swallows. Behav Ecol 12:496-500

Wilk T, Cichon M, Wolff K (2008) Lack of evidence for improved immune response of extrapair nestlings in collared flycatcher Ficedula albicollis. J Avian Biol 39:546-552

Yasui Y (1998) The 'genetic benefits' of female multiple mating reconsidered. Trends Ecol Evol 13:246-250 


\section{$785 \quad$ Figure captions}

786 Fig. 1 Schematic representation of linear fitness reaction norms of two offspring genotypes (represented by lines) to illustrate potential effects of genotype-by-environment interactions on

788 the genetic benefits of mate choice. a Genotypes show no phenotypically plastic response, the

789 slopes of their reaction norms are identical and equal zero (parallel reaction norms, no

790 genotype-by-environment interaction). b Genotypes show a phenotypically plastic response, the

791 slopes of their reaction norms are identical, but different from zero (parallel reaction norms, no

792 genotype-by-environment interaction). c Genotypes show a phenotypically plastic response, the

793 slopes of their reaction norms are different, but reaction norms do not cross within the range of

794 environmental conditions experienced (genotype-by-environment interaction with non-crossing

795 reaction norms). d Genotypes show a phenotypically plastic response, the slopes of their

796 reaction norms are different, and reaction norms cross within the range of environmental

797 conditions experienced (genotype-by-environment interaction with crossing reaction norms,

798 ecological cross-over). Relative genetic fitness benefits from preferring a male siring either one

799 or the other offspring genotype are identical (a), (b), differ in magnitude (c), or may even be

800 reversed (d) across environments.

801 
$802 \quad$ Figures

803 Figure 1

$804 \quad$ (a)

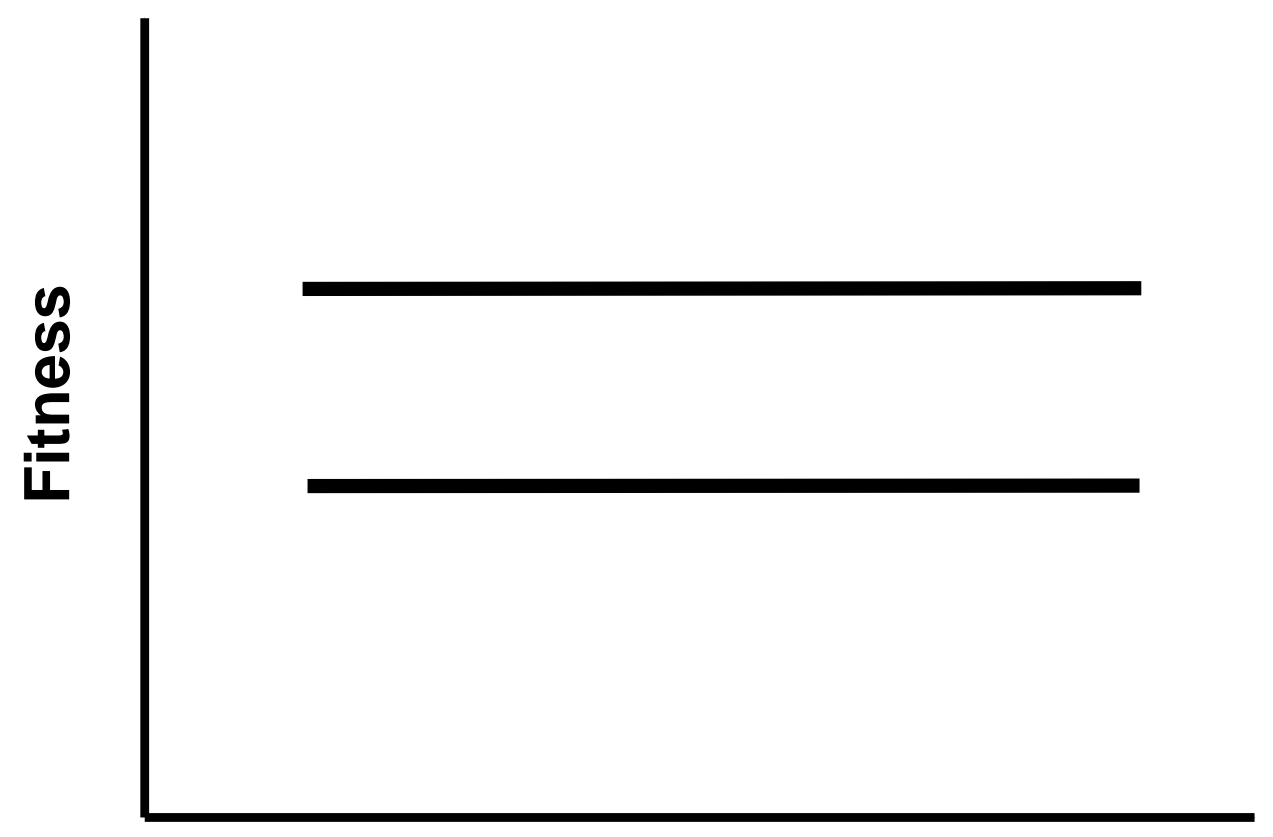

805

$806 \quad$ (b)

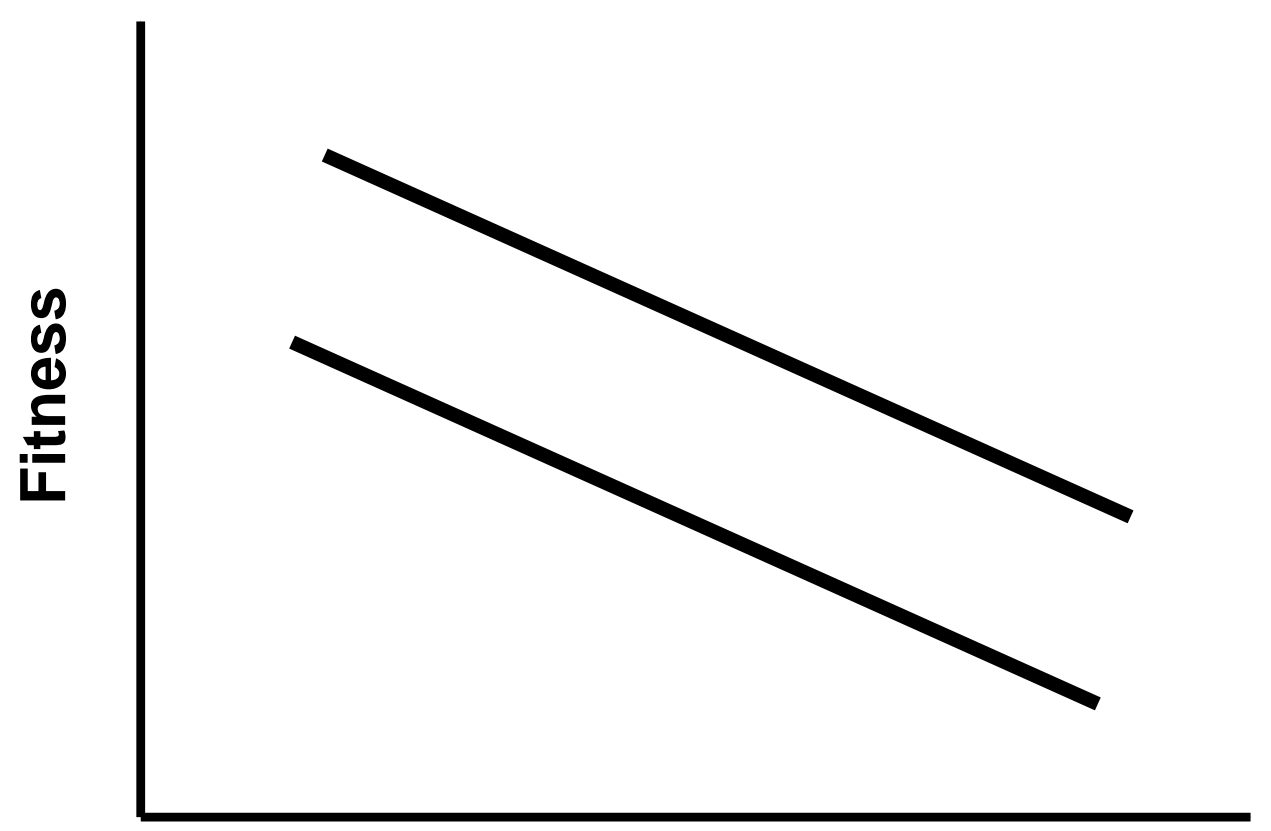




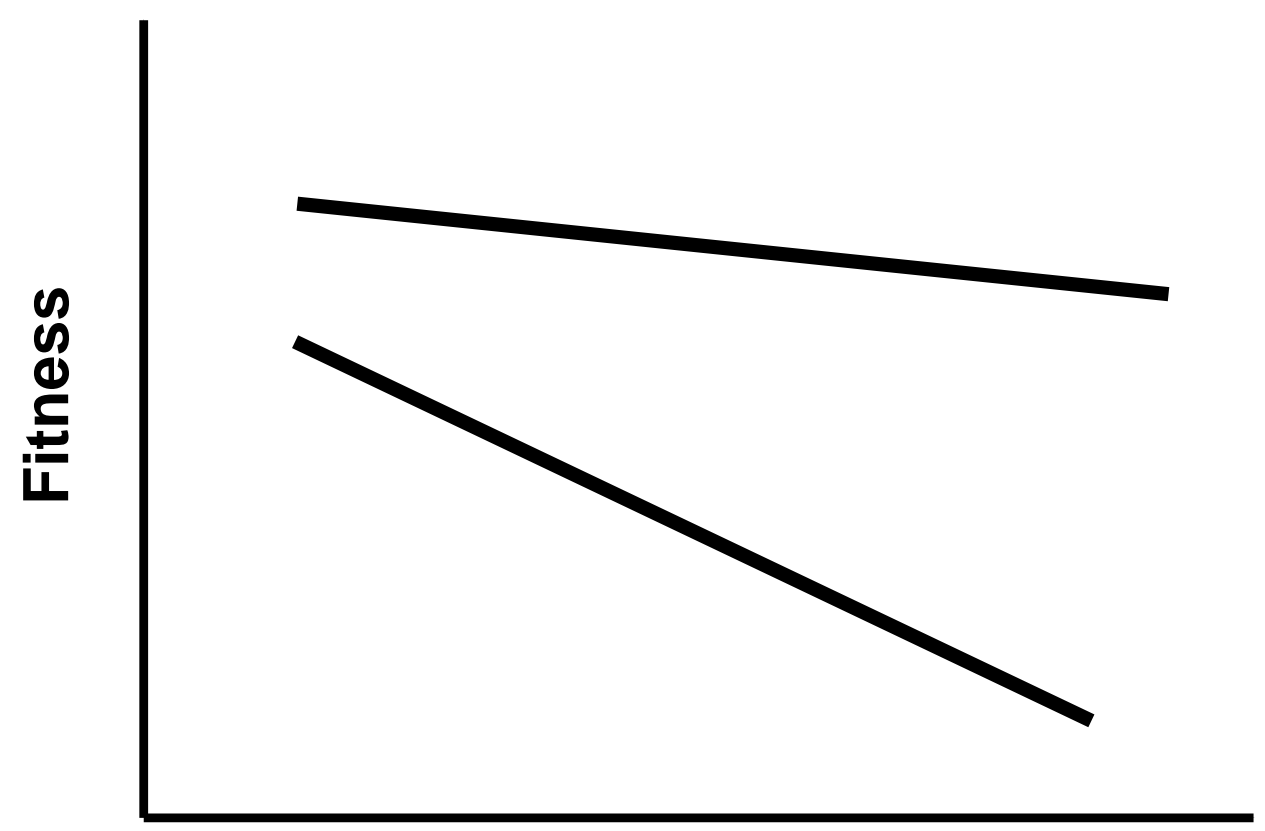

810

811

(d)

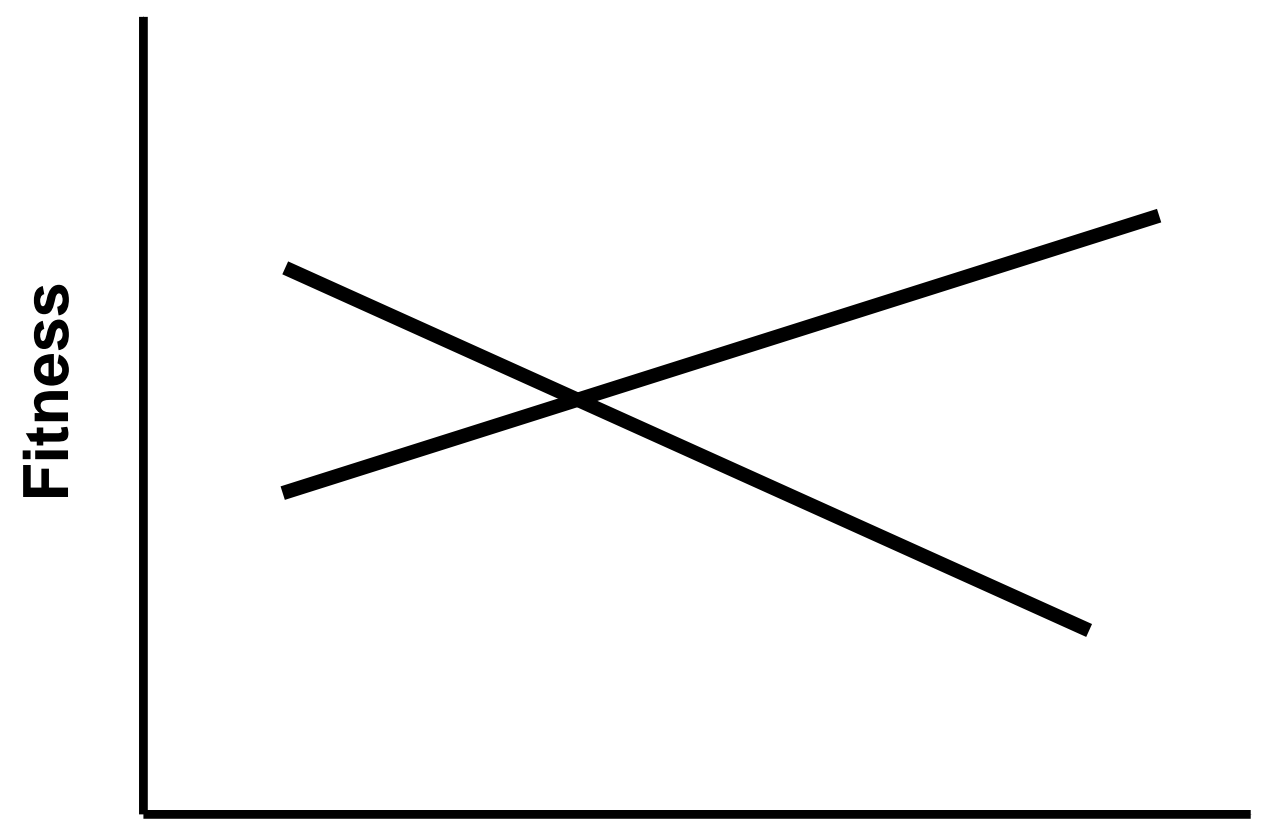

813 German abstract for article 10336-683: A review and perspective on context-dependent genetic

814 effects of extra-pair mating in birds 
816 Kontextabhängige genetische Effekte von Fremdkopulationen bei Vögeln: Review und

819 Der evolutionäre Ursprung und die Aufrechterhaltung von außerpaarlichem

820 Kopulationsverhalten bei Vögeln sind in den letzten Jahrzehnten intensiv untersucht worden.

821 Allerdings konnte bisher kein Konsens bezüglich des adaptiven Nutzens dieses Verhaltens für

822 Vogelweibchen erzielt werden. Die genetische Vorteile-Hypothese postuliert, dass

823 Fremdkopulationspartner Genvarianten von höherer Qualität oder besserer Kompatibilität im

824 Vergleich zum sozialen Paarpartner aufweisen, was zu Nachkommen von höherem

825 Reproduktionswert führen würde. Ein häufig genutzter Ansatz zur Überprüfung dieser

826 Hypothese besteht darin, mütterliche Halbgeschwister in Bruten mit multiplen Vaterschaften

827 bezüglich fitness-relevanter Merkmale zu vergleichen. Die Ergebnisse solcher Vergleiche sind

828 allerdings nicht konsistent. In diesem Beitrag diskutiere ich die Idee, dass das Ausmaß

829 genetischer Fitnessvorteile aus Fremdkopulationen vom Umweltkontext abhängt. Kontext-

830 abhängige genetische Effekte wurden bisher nur bei fünf Singvogelarten nachgewiesen. In

831 keiner der betreffenden Studien wurden jedoch die entscheidenden Umweltvariablen

832 experimentell manipuliert. Auch wurden die potentiell konfundierenden Effekte von

833 differentiellem mütterlichen Investment in Abhängigkeit der Vaterschaft zumeist nicht

834 kontrolliert. Eine Reihe von hochqualitativen Datensätzen zu den Fitnesskonsequenzen von

835 Fremdkopulationsverhalten ist verfügbar, die bezüglich ihrer Umweltabhängigkeit (re-)

836 analysiert werden könnten. Dies gilt, sofern relevante Umweltgradienten erfasst wurden und

837 ihre Berücksichtigung a priori plausibel gemacht werden kann. Relevante Variation könnte

838 zum Beispiel den Zeitpunkt des Brütens in gemäßigten Breiten, die Reihenfolge des Schlupfes,

839 aber auch das Geschlecht der Nachkommen umfassen. In erster Linie sind jedoch

840 experimentelle Ansätze nötig, die fitnessrelevante Gradienten der Umwelt wie

841 Futterverfügbarkeit oder Parasitenbelastung systematisch und graduell variieren. Die

842 Kontextabhängigkeit genetischer Effekte von Fremdkopulationen könnte möglicherweise

843 erlauben, widersprüchliche Resultate verschiedener Studien innerhalb und zwischen Arten zu

844 integrieren. Eine solche Kontextabhängigkeit könnte aber auch ganz allgemein helfen zu

845 verstehen, unter welchen Umweltbedingungen Selektion eine weibliche Paarungspräferenz für

846 Fremdkopulationspartner aufrechterhält. Dies hätte potenziell weit reichende Folgen für die

847 Ökologie und Evolution von Paarungspräferenzen und die Aufrechterhaltung genetischer

848 Variation von (sexuell) selektierten Merkmalen. 